Viso - Cadernos de estética aplicada Revista eletrônica de estética

ISSN 1981-4062

No 16, jan-jun/2015

http://www.revistaviso.com.br/
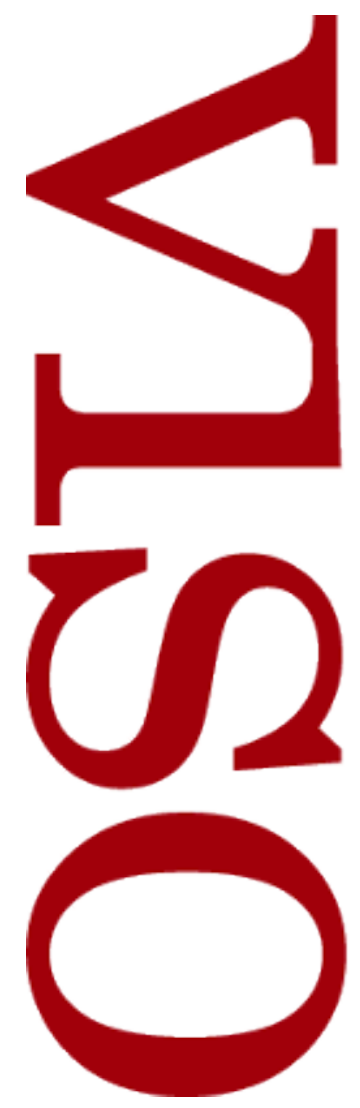

\title{
De onde se vê? Duplicação e dissolução do olhar em Alfred Hitchcock e David Lynch
}

Ulysses Pinheiro

Universidade Federal do Rio de Janeiro (UFRJ)

Rio de Janeiro, Brasil 


\section{RESUMO}

De onde se vê? Duplicação e dissolução do olhar em Alfred Hitchcock e David Lynch

Este artigo compara dois filmes, Janela indiscreta, de Alfred Hitchcock, e Estrada perdida, de David Lynch, com o objetivo de mostrar que eles ilustram duas maneiras distintas de caracterizar o olhar inumano da percepção cinematográfica, tal como ele foi descrito por Gilles Deleuze. Essas duas maneiras distintas não foram discriminadas pelo próprio Deleuze, mas convergem em direção a sua crítica à hermenêutica.

Palavras-chave: Hitchcock - Lynch - percepção - representação - interpretação

\section{ABSTRACT}

Where does one see from? Duplication and Dissolution of Vision in Alfred Hitchcock and David Lynch

This paper compares two movies, Rear Window, by Alfred Hitchcock, and Lost Highway, by David Lynch, in order to show that they illustrate two different ways of characterizing the non-human eye of the cinematographic perception, such as it was portrayed by Gilles Deleuze. These two distinct ways were not discriminated by Deleuze himself, but they both converge towards his critics against hermeneutics.

Keywords: Hitchcock - Lynch - perception - representation - interpretation 
PINHEIRO, U. "De onde se vê? Duplicação e dissolução do olhar em Alfred Hitchcock e David Lynch". In: Viso: Cadernos de estética aplicada, v. IX, n. 16 (jan-abr/2015), pp. 103-115.

DOI: 10.22409/1981-4062/v16i/198

Aprovado: 15.06.2015. Publicado: 30.07.2015.

(C) 2015 Ulysses Pinheiro. Esse documento é distribuído nos termos da licença Creative Commons Atribuição-NãoComercial 4.0 Internacional (CC-BY-NC), que permite, exceto para fins comerciais, copiar e redistribuir o material em qualquer formato ou meio, bem como remixá-lo, transformá-lo ou criar a partir dele, desde que seja dado o devido crédito e indicada a licença sob a qual ele foi originalmente publicado.

Licença: http://creativecommons.org/licenses/by-nc/4.0/deed.pt_BR

Accepted: 15.06.2015. Published: 30.07.2015.

(C) 2015 Ulysses Pinheiro. This document is distributed under the terms of a Creative Commons Attribution-NonCommercial 4.0 International license (CC-BY-NC) which allows, except for commercial purposes, to copy and redistribute the material in any medium or format and to remix, transform, and build upon the material, provided the original work is properly cited and states its license.

License: http://creativecommons.org/licenses/by-nc/4.0/ 
Em Cinema 1: A imagem-movimento, Gilles Deleuze reverte a famosa crítica de Henri Bergson ao cinema, usando contra ele sua própria teoria da percepção': longe de supor uma continuidade entre nossa percepção natural e a percepção cinematográfica, diz Deleuze, deveríamos admitir, nos termos do próprio Bergson, que há entre elas uma diferença de natureza. Segundo Deleuze, enquanto, na percepção natural, as coisas são figuradas segundo os parâmetros da unidade do ponto de vista e da representação do movimento como sucessão de posições projetadas sobre um plano espacial, na percepção cinematográfica lidamos diretamente com imagens-movimento, isto é, com cortes móveis do tempo e com a multiplicação dos pontos de vista. Poderíamos generalizar para todo o cinema aquilo que Deleuze diz de Vertov:

Em Vertov, o intervalo de movimento é a percepção, o olhar de relance, o olho. Simplesmente, o olho não é o olho demasiado imóvel do homem, é o olho da câmera, isto é, um olho na matéria, uma percepção tal como existe na matéria [....] A correlação entre uma matéria não humana e um olho sobre-humano é a própria dialética, pois é, principalmente, a identidade de uma comunidade da matéria com um comunismo do homem².

Ou, como afirmou o próprio Vertov, o cine-olho é o que "engancha qualquer ponto do universo a outro em qualquer ordem temporal". ${ }^{3}$ Poderíamos dizer: uma espécie de anarco-comunismo do olhar.

Gostaria de propor, entretanto, uma distinção no interior do que Deleuze chama de percepção cinematográfica: ao fracionar o olhar demasiado humano em um olho-matéria disperso e móvel, o cinema defronta-se com, pelo menos, duas possibilidades. A primeira é a de construir uma espécie de simulacro de olhar humanizado. Tal simulacro, embora não reproduza exatamente o ponto de vista unificado da percepção natural, o emula em um duplo que, sem deixar de desmembrá-lo em percepções inumanas, ao mesmo tempo mantém, virtualmente, no horizonte, a unidade do ponto de vista e o espaço da representação. A segunda possibilidade é a de investir, nesse duplo, a dissolução dos pontos de vista, até o momento em que não se trata mais de uma representação qualquer, mas antes da destruição da ideia mesma de duplicação. Para ilustrar essas duas possibilidades do cinema, recorrerei a dois filmes que, tradicionalmente, foram interpretados como uma reflexão sobre o próprio cinema: o exemplo da primeira possibilidade será o filme Janela indiscreta (1954), de Alfred Hitchcock4; o exemplo da segunda, o filme Estrada perdida (1997), de David Lynch. ${ }^{5}$ Antes, porém, de contrapor esses dois filmes como duas possibilidades para o cinema, devo fazer um esclarecimento e uma advertência.

O esclarecimento diz respeito ao significado em que tomarei a palavra "representação" daqui por diante. Disse acima que a primeira possibilidade de produzir uma percepção cinematográfica mantém, enquanto a segunda dissolve, o espaço da representação. $O$ que significa exatamente, nesse contexto, "representação"? No texto intitulado "Diderot, Brecht, Eisenstein" ${ }^{\prime}$, Roland Barthes nos propõe uma indicação: 
A representação, diz ele, não se define diretamente pela imitação: se abandonarmos as noções de "real", de "verossímil", de "cópia", haverá sempre "representação" enquanto alguém (autor, leitor, espectador) dirigir seu olhar para um horizonte e nele recortar a base de um triângulo de que seu olho (ou sua mente) será o vértice. O Organon da Representação, conclui Barthes, terá como duplo fundamento a soberania do recorte e a unidade daquele que recorta.

Nesse sentido preciso, não só o cinema e o teatro são expressões de uma "geometria do olhar": também a literatura clássica (isto é, legível) é um discurso representativo, geométrico, parte das "artes dióptricas", para usar a expressão do próprio Barthes. ${ }^{7}$

Disse acima que faria um esclarecimento e uma advertência. Ora, é justamente a consideração de Barthes sobre a natureza das "artes dióptricas" que me permite passar do esclarecimento acerca do significado de "representação" para a advertência, que tem por objeto a noção de interpretação. Segundo o "fundamento geométrico da representação", próprio do cinema, do teatro e da literatura tradicionais, a partir do qual, diz Barthes, "as coisas são sempre vistas de algum lugar", o recorte do quadro que mostra o espetáculo requer um "tema fetichista": "Esse lugar de origem é sempre a Lei: lei da sociedade, lei da luta, lei do sentido. A partir daí, toda arte militante só pode ser representativa, legal". ${ }^{8} \mathrm{O}$ que Barthes quer dizer é que, por sua própria natureza, todo quadro apresenta um sentido a ser valorado: o recorte de uma cena só se justifica porque seleciona o que tem valor e o separa do sem-sentido. Ora - e aqui enuncio minha advertência -, eu disse acima que recorrerei a dois filmes que tradicionalmente foram interpretados como propondo uma reflexão sobre o próprio cinema para ilustrar duas de suas possibilidades intrínsecas. Devo advertir, porém, que o resultado final de minha análise será o abandono da noção mesma de "interpretação": na verdade, veremos, os dois filmes só podem ser compreendidos como exemplos do que quero ilustrar se não quisermos, de forma alguma, "interpretá-los".

Comecemos, então, a examinar o que chamei acima de "primeira possibilidade do cinema", ilustrada pelo filme Janela indiscreta. O resumo da trama, para os que não se recordam dela, é o seguinte: um repórter fotográfico (vivido por James Stewart), confinado a uma cadeira de rodas por causa de uma perna quebrada, passa a observar compulsivamente o comportamento dos vizinhos de fundos de seu prédio (o título original do filme, lembremos, é Rear Window); suas observações o levam a suspeitar de que um de seus vizinhos (Raymond Burr) assassinou sua esposa, mas ele não consegue convencer a namorada (Grace Kelly) de sua hipótese. Quando ela, entretanto, é contaminada progressivamente por suas suspeitas, parte em busca de evidências incriminadoras, invadindo furtivamente o apartamento do vizinho, observada por seu namorado imóvel do outro lado do jardim interno do prédio. Finalmente, o assassino descobre que estava sendo vigiado e tenta matar o observador, indo até seu apartamento; o Repórter é salvo no último minuto. Neste momento, é importante mencionar novamente Barthes para dizer que o tema de uma representação, evidentemente, não interessa: o que importa é o gestus social que ela codifica (daí a 
aproximação que Barthes promove entre Diderot, Brecht e Eisenstein). O gestus em questão é, claramente, o de representar a posição do espectador de cinema, que, sentado imóvel em sua cadeira, observa cenas recortadas pela janela diante dele. Impossível não lembrar, neste momento, da Carta a d'Alembert, na qual Jean-Jacques Rousseau condena o teatro clássico francês, e com ele o então nascente drama burguês, justamente devido a essa imobilidade doentia a que condenava o espectador a saber: à atitude de observar uma cena com o distanciamento de um voyeur. Antecipando em alguns pontos o estruturalismo do século XX, Rousseau não condenava os espetáculos pelo conteúdo das peças, mas antes pelo esquema mental que mobilizavam: o "perigo das imagens", diz ele, não reside naquilo que é visto, mas na posição que elas demandam do observador passivo, sentado em uma sala escura, como se a única parte viva de seu corpo fosse seu olho. Uma sociedade do espetáculo, diz Rousseau, seria aquela em que passaríamos a observar com indiferença o sofrimento e a desigualdade dos outros homens, como ocorre quando passamos, apressados, por mendigos e crianças jogadas nas calçadas.

Observemos um instante, então, James Stewart observando seu vizinho. Em primeiro lugar, pensemos na abertura do filme, quando as cortinas literalmente levantam-se na janela, mostrando os apartamentos e o pátio dos fundos, para que o espetáculo comece. ${ }^{9} \mathrm{O}$ recurso tradicional para indicar que uma cena deve ser vista como exprimindo o ponto de vista de uma personagem é partir de uma tomada objetiva de seus olhos e, em seguida, alterná-la com o objeto visto. No presente caso, porém, ao emular o olhar do Repórter, antecipando a ação que ele efetivamente realizará no restante do filme, a câmera nos revela, na sequência, que ele está, de fato, descansando, de costas para a janela e com os olhos fechados. O olho que observa o pátio interno de seu prédio é uma espécie de prótese móvel de nosso olho de espectadores do filme, enunciando visualmente, assim, a duplicação do olhar que estará em jogo durante toda a trama: se, por um lado, é verdade que olhamos através do olhar do Repórter fotográfico, por outro lado, o que interessa mais profundamente é olharmos seu olhar. A alternância entre olho e objeto visto não é apenas, como tradicionalmente é o caso, um recurso para marcar formalmente a introdução do ponto de vista subjetivo, mas funciona, antes, como uma espécie de distanciamento brechtiano para que nós, os espectadores, possamos ver "de fora" o olhar do Repórter. Para que essa "observação da observação" ocorra, portanto, é preciso promover, desde o início do filme, no primeiro ato, quando as cortinas se levantam, a distinção entre esses dois pontos de vista, que nem sempre se confundirão ao longo da trama.

Outra cena importante para entender o tipo de representação que está em jogo nesse filme é aquela na qual nosso olhar é convidado a ver o olhar do Repórter observando seu vizinho, em um momento em que a suspeita já está instalada. ${ }^{10}$ Devemos notar que a câmera oscila entre o ponto de vista objetivo, a partir do qual vemos o Repórter olhar o suspeito através da teleobjetiva de sua câmera fotográfica ${ }^{11}$, e o ponto de vista subjetivo do Repórter, que passa a ser investigado por nosso próprio olhar. Há uma série de 
duplicações desse tipo que não eliminam, mas antes permitem, que o ponto de vista do Repórter seja erigido como a unificação a partir da qual toda a cena é construída: ao vermos o Repórter vendo, nos distanciamos dele apenas para melhor submergir mais uma vez em seu ponto de vista unificador, apagando nossa própria identidade para que a dele possa se impor. O resultado dessas idas e vindas é a construção de uma espécie de olhar virtual, que domina todos os demais, correspondendo ao mesmo tempo à dispersão do olho-câmera e à unidade de um ponto de vista único. ${ }^{12}$

É significativo que a profissão do observador seja a de repórter fotográfico: enquanto sua intensa movimentação, cobrindo guerras em lugares distantes, resulta nas imagens congeladas em diversas fotografias penduradas na parede de seu quarto, a imobilidade causada pela sua perna quebrada permite que imagens em movimento apareçam diante dele, enquadradas por sua janela. O vértice do triângulo ótico barthesiano tem de ser uno e imóvel para que o movimento do quadro apareça - assim, no final do filme, quando o Repórter tenta livrar-se do ataque do assassino, disparando contra ele flashes de sua máquina fotográfica, o que ele tenta fazer é, justamente, imobilizá-lo.

Essas imagens produzidas a partir de um ponto fixo e imóvel não são apenas, como reconhece Rousseau, ainda na Carta a d'Alembert, uma ocasião para um voyeurismo distante: elas também promovem um tipo de identificação com as personagens em cena, de tal modo que, se as imagens não têm o poder de nos ensinar a virtude, elas têm, entretanto, a capacidade de revelar, como em um espelho, nossos vícios mais secretos. Um tema caro a Hitchcock, o da "direção dos espectadores", aparece claramente aqui: nós, que entramos no cinema movidos talvez pela busca de uma distração inocente para nos livrar do tédio, somos levados a "cair em tentação" juntamente com a personagem de James Stewart, uma espécie de Adão paralítico, tomado por uma desmedida vontade de saber que emerge aos poucos, insensivelmente, de sua atenção dispersa aos acontecimentos banais de sua vizinhança. Essa imagem em espelho do observador, tornada evidente pela duplicação do olhar reflexivo que dirigimos a nós mesmos ao olharmos para o Repórter, mostra-se claramente pelo caráter especular dos apartamentos do observador e do observado: enquanto, no primeiro, um homem imobilizado é ajudado por sua namorada amorosa, no segundo, uma mulher doente e imobilizada na cama é vigiada por seu marido, que a odeia. Mas as inversões reflexivas atingem seu ápice no final do filme, quando o observado sai do enquadramento estabelecido pela janela de seu apartamento e dirige-se ao apartamento do observador, confrontando-o com a pergunta decisiva: "O que você quer de mim?". ${ }^{13} \mathrm{O}$ observador, notemos, não responde a essa pergunta: na construção do olhar duplo pelo qual nos identificamos com o olhar do Repórter, a "impertinência" de uma imagem que, revoltada com sua condição passiva, interpela o olho que a vê não pode ter outra resposta que o silêncio, pois esse último é o que constitui nossa posição de espectadores impassíveis de um crime ou - fazendo uma concessão ao cristianismo de Hitchcock - de um pecado.

A análise da segunda possibilidade do cinema, a ser ilustrada pelo filme Estrada perdida 
(Lost Highway), encontra nessas cenas finais de Janela indiscreta uma repercussão curiosa. Naquela que é talvez sua cena mais famosa, a da festa onde o Músico (interpretado por Bill Pullman) encontra Mistery Man (vivido por Robert Blake), os papéis estão invertidos: é o protagonista do filme que desempenha a função de ser o observado, enquanto que Mistery Man é o observador. É na festa que a imagem interpela pela primeira vez o observador, e, novamente aqui - mas por razões diversas das de Janela indiscreta, como veremos a seguir -, sem conseguir obter uma resposta. A pergunta, desta vez, não é mais "O que você quer de mim?", mas sim "Quem é você?", seguida de outra: "Como você fez isso?". ${ }^{14}$

"Como você fez isso?", isto é: como você conseguiu filmar minha casa desde esses pontos de vista múltiplos e impossíveis? Uma pista para entender a diferença entre o observador de Janela indiscreta e o observador de Estrada perdida é o riso perturbador que Mistery Man dá como resposta, em uma forma elusiva, mas expressiva, de silêncio: passamos do registro do trágico para o do cômico, ainda que se trate de uma espécie de humor negro.

Lembremos brevemente do "enredo" de Estrada perdida - se é que isso é possível, ${ }^{15} \mathrm{O}$ filme apresenta uma estrutura ao mesmo tempo especular (com a duplicação de duas situações simétricas) e de looping temporal (a última cena "repete" a primeira - mas, como já ensinou Deleuze, a verdadeira repetição só pode ser o retorno da diferença, e algo muda nessa repetição). Dada essa estrutura complexa, o melhor é resumir ao máximo o plot do filme; encontramos, no site do IMDb, a seguinte sinopse: "Depois de um encontro bizarro em uma festa, um saxofonista de jazz é falsamente acusado pelo assassinato de sua esposa e enviado para a prisão, onde inexplicavelmente metamorfoseia-se em um jovem mecânico e começa a levar uma nova vida". ${ }^{16}$ Esse resumo simplificado está muito longe, contudo, de fazer justiça à complexidade de sua trama real, construída através do cruzamento dos diversos mundos virtuais e do tempo circular no qual ela se desenvolve, promovendo, ao final, um "curto-circuito" entre eles. Graças à manipulação de signos visuais, que interferem na e "contaminam" a linearidade de sua trama meramente "literária", Lynch consegue parasitar o enredo simples e clássico do filme noir com esse mundo paralelo. Em Estrada perdida, uma mesma personagem é interpretada por dois atores, ou o mesmo ator interpreta duas personagens, ou o mesmo ator interpreta a mesma personagem interagindo com seus duplos em outro mundo possível. ${ }^{17} \mathrm{O}$ próprio Lynch, que sempre se recusa a dar "explicações" para seus filmes (basta lembrar de suas curiosas entrevistas, em que ele sempre, comicamente, diz coisas como: "aí então eu tive uma ideia, e então pedi para os atores realizarem essas ideias, e os atores realizaram essas ideias, etc."), fez um pequeno resumo de quatro linhas, à guisa de introdução ao texto publicado do roteiro de Estrada perdida; eis como ele apresentou seu filme: 
Um filme noir de horror do século XXI.

Uma investigação gráfica sobre crises de identidade paralela.

Um mundo onde o tempo está perigosamente fora de controle.

Uma viagem aterrorizante na Estrada perdida. ${ }^{18}$

Esqueçamos, pois, do "tema" do filme, e pensemos no que ele nos mostra; há, para usar o vocabulário de Deleuze, uma imagem-movimento que perpassa todo o filme, a da câmera usada por Mistery Man para filmar a vida de Fred/Pete. Fred e sua esposa recebem, no início da história, tapes de sua própria casa. O primeiro vídeo a mostra do lado de fora, mas os seguintes mostram a casa por dentro. ${ }^{19}$

Diferentemente do olhar em Janela indiscreta, no filme de Lynch o ponto de vista subjetivo não é unificado em um observador imóvel: na transposição das imagens externas da casa para as imagens internas, trata-se de um ponto de vista de lugar nenhum. Ninguém que pertença a este mundo - isto é, que possa ser localizado no interior do espaço unificado e uno habitando no interior do mundo atual - responde por esse olhar; não há, mais, portanto, a duplicação do olhar, mas sua fragmentação e dissolução. Essas imagens internas só podem ser (e não são) a dos próprios habitantes da casa. Estamos aqui muito mais perto da dispersão do olho-câmera ou do olho-matéria de Vertov, tal como apresentados pelo bergsoniano Deleuze: as imagens são imanentes à própria realidade, sendo impossível remetê-las a um ponto de vista unificado (como no caso do Repórter/espectador de Hitchcock). Ao invés da "direção de espectadores" e do universo de passividade e culpa (onde temos de nos defrontar com o "perigo das imagens", já nos advertia Rousseau), Estrada perdida habita a região da divisão esquizofrênica e do medo, como podemos ver na cena final do filme. ${ }^{20}$ Ou seja, o que deixa de existir na câmera subjetiva de Lynch é a própria subjetividade: não é mais possível haver um olhar subjetivo, pois o que nos é dado a ver é um olho-matéria disperso e disjunto.

Ora, o que desaparece juntamente com o fim da subjetividade fílmica e do ponto de vista subjetivo das personagens e do espectador é a própria possibilidade de interpretar o filme. ${ }^{21}$ É isso que a longa linhagem dos candidatos a hermeneuta da obra de Lynch não compreendeu. Dessa linhagem, Slavoj Žižek é um dos mais recentes; em um ensaio dedicado a Estrada perdida, publicado em seu livro Lacrimæ rerum, ele nos oferece uma interpretação psicanalítica do filme, não sem antes reconhecer que ela corre o risco de cair em um reducionismo psicologizante:

Contudo, essa interpretação psicanalítica direta também tem seus limites. Para falar em termos de certo modo stalinistas, devemos rejeitar dois tipos de desvios: o desvio psicoreducionista direitista (o que acontece a Pete é apenas uma alucinação de Fred, da mesma maneira que os dois criados idosos e corruptos são apenas a alucinação do narrador em $A$ volta do parafuso, de Henry James) e a insistência esquerdista, anarcoobscurantista e antiteórica de que deveríamos renunciar a todo esforço interpretativo e nos deixar conduzir pela ambiguidade e pela riqueza absolutas da textura sonora e visual do filme - qualquer uma é pior do que a outra, como diria Stalin... ${ }^{22}$ 
O que Žižek não consegue perceber é que o que ele chama de visão "anarcoobscurantista" é a única forma de ler o filme de maneira não-reducionista. Em sua apresentação de falsas opções exclusivas, Žižek nos conduz ao seguinte dilema: ou bem hermenêutica ou bem um formalismo vazio - dilema que lembra um outro, com o qual aqueles que pensam a política fora dos esquemas da democracia representativa, como é, ironicamente, o caso do próprio Žižek, já devem estar bastante familiarizados: civilização ou barbárie. Eis a conclusão principal da interpretação psicanalítica do filme proposta por Žižek:

Será muito mais produtivo insistir no fato de a forma extremamente circular da narrativa em Estrada perdida transmitir diretamente a circularidade do processo psicanalítico. Em outras palavras, um ingrediente crucial do universo de Lynch é uma frase, uma cadeia significativa, que ressoa como um Real que persiste e regressa sempre - uma espécie de fórmula básica que suspende e atravessa o tempo. ${ }^{23}$

Segundo essa interpretação, a encenação psicanalítica que vemos em Estrada perdida poderia ser reconduzida a um triângulo de sabor edipiano:

Numa análise mais circunstanciada, devemos concentrar nossa atenção nas três cenas mais notáveis do filme: a explosão de raiva do senhor Eddy (de Dick Laurent) contra o condutor; a conversa telefônica de Fred com Mistery Man na festa; e a cena em casa de Andy, em que Alice [Patricia Arquette] é confrontada com o plano pornográfico em que é possuída por trás. Cada uma dessas três cenas define uma das três personagens com quem o herói está relacionado: Dick Laurent como o pai de superego excessivo/obsceno; Mistery Man como conhecimento sincrônico fora do espaço e do tempo; Alice como tela-fantasia da fruição excessiva. ${ }^{24}$

É sintomático, se nos for permitido fazer uso do vocabulário psicanalítico do próprio Žižek, que, em sua análise, nada dependa do fato de que a história se desenrola em um filme: ele bem poderia estar analisando um romance, um conto, uma poesia. Essa indiferença em relação ao meio visual no qual a trama se desenrola - e, no entanto, já o sabemos, o meio é a mensagem - só é possível quando se adota, em relação a ela, a postura hermenêutica. Deleuze já o disse, a propósito de Artaud (mas poderia ser também sobre Lynch): "nada de significante, não interprete nunca!"”25 - ou antes: é preciso que algo do organismo seja preservado, para que o processo de desterritorialização continue, e, juntamente com o organismo, é também necessário conservar "pequenas provisões de significância e de interpretação [....], inclusive para opô-las a seu próprio sistema, quando as circunstâncias o exigem, quando as coisas, as pessoas, inclusive as situações nos obrigam". ${ }^{26}$ A falência da interpretação é não propriamente anunciada ou descrita, mas incorporada à linguagem de forma positiva: ela passa a ser a própria forma do pensamento e o elemento no qual se pensa. A semiótica das imagens, nos ensina Deleuze, nos libera das falsas oposições entre hermenêutica e formalismo. É no plano virtual criado pela câmera descentrada portada por Mistery Man que podemos $1 e r^{27}$ Lynch. 
A certa altura do filme, Mistery Man diz a Fred que faz seus filmes a mando de Mr. Eddy/ Dick Laurent. Curiosamente, Mr. Eddy/Dick Laurent está morto, e é com sua morte que o filme começa ("Dick Laurent está morto", diz a voz no interfone - sem que haja ninguém na porta dizendo isso). Não se trata aqui, como sugere Žižek, de nos contentarmos com a banalidade de afirmar que a ficção pode tudo, inclusive suportar contradições, tais como a de uma voz sem emissor. E não se trata disso justamente porque tal "interpretação" já supõe a divisão entre ficção e realidade, e entre o real e o possível. Há outra clivagem mais fundamental, nos ensina Deleuze/Bergson: o real é composto pelo atual e pelo virtual, e é nesse último que a diferença se insinua, tão real quanto o que é atual. Se, como diz Lynch, o universo de Estrada perdida é o mesmo de Twin Peaks, então o condutor do carro invisível na primeira cena e visível multiplamente na última, ambas ao som de David Bowie, exprimem justamente esse ponto de vista de lugar nenhum.

Barthes distingue, no mesmo texto que citei inicialmente, entre duas formas de conceber a arte, uma delas musical e outra ótica; ora, no percurso que aqui fizemos, passamos justamente de Janela indiscreta, com seu Repórter Fotográfico, para Estrada perdida, com seu Músico - ou seja, da arte clássica (legível), representativa, interpretável, ótica, para aquela que cumpriria a expectativa contida no título do livro-manifesto de Susan Sontag: contra a interpretação. ${ }^{28}$

* Ulysses Pinheiro é professor associado do Departamento de Filosofia da UFRJ.

${ }^{1}$ DELEUZE, G. Cinema 1: A imagem-movimento. São Paulo: Brasiliense, 1985.

2 Ibidem, p. 44.

${ }^{3}$ VERTOV, D. Articles, Journaux, Projets. Traduction et notes par Sylviane Mossé et Andrée Robel, Paris: Union générale d'éditions, 1972, pp. 126-127 (apud DELEUZE, G. Op. cit., p. 106.

${ }^{4}$ HITCHCOCK, A. Rear Window. Produção: James C. Katz, Alfred Hitchcock. EUA, Paramount Pictures (112 $\mathrm{min}), 1954.1$ bobina cinematográfica.

${ }^{5}$ LYNCH, D. Lost Highway. Produção: Deepak Nayar, Tom Sternberg, Mary Sweeney. EUA, Focus Features (134 min), 1997. 1 bobina cinematográfica. Cenas disponíveis em: YouTube, movieclipsFILMR. http://www.youtube.com/user/movieclipsFILMR. Acesso em: 21/04/2015. Há uma já longa tradição crítica que relaciona Lynch a Hitchcock. Ver, por exemplo, o texto de Olivier de Bruyn sobre Estrada perdida. Segundo De Bruyn, trata-se de um filme que "fala de paranoia e de identidade, de esquizofrenia e de inquietude do sentimento, uma espécie de obra-prima de angústia cerebral que deve muito a Hitchcock e a Freud”. DE BRUYN, O. Crítica cinematográfica a Lost Highway publicada no jornal L'Evénement du Jeudi em 16/01/1997. In: Cinémathèque Française. http://www.cinematheque.fr/fr/dans-salles/hommages-retrospectives/revues-presse/lynch/losthighway.html. Acesso em 24/04/2015.

${ }^{6}$ BARTHES, R. "Diderot, Brecht, Eisenstein". In: O óbvio e o obtuso. Rio de Janeiro: Nova Fronteira, 1990, pp. 85-92.

${ }^{7}$ Ibidem, p. 86. 
8 Ibidem, p. 91.

9 Cf. http://www.youtube.com/watch?v=6ncHqP_CsrY. Cenas disponíveis em: YouTube, movieclipsFILMR. http://www.youtube.com/user/movieclipsFILMR. Acesso em: 21/04/2015.

10 No site movieclipsFILMR, essa cena é intitulada "A Closer Look at the Salesman". Cf. http://www.youtube.com/watch?v=w5pn48wzBuw. Acesso em: 21/04/2015.

11 A objetividade da representação é aumentada pelo recorte circular da teleobjetiva, que circunscreve a imagem do vizinho.

12 Essa mesma duplicidade pode ser observada em outros filmes de Hitchcock; assim, por exemplo, em Rope (título sugestivo e simples, traduzido estranhamente, em sua versão brasileira, por Festim diabólico), as tomadas são interconectadas, através de truques de montagem, em um único plano-sequência sem cortes (composto por dez rolos de filme, cuja duração oscila entre 00:04:37 - o mais curto - e 00:10:06 - o mais longo). A mobilidade da câmera que percorre o cenário contrasta com o fluxo contínuo que unifica esse percurso. Segundo o Oxford Dictionary, a palavra "rope" significa "a very strong thick string made by twisting thinner strings, wires, etc. together". Os dez planos-sequência fundem-se, assim, uns aos outros como os fios de uma só corda aparentemente una e simples.

${ }^{13}$ Cf. http://www.youtube.com/watch?v=oowcsynjIwc. Acesso em: 21/04/2015.

${ }^{14}$ Cf. http://www.youtube.com/watch?v=qZowK0NAvig. Acesso em: 24/04/2015.

${ }^{15}$ De Bruyn, em sua crítica ao filme mencionada acima (cf. nota 6), afirma que "Estrada perdida é um filme não-narrável [....] Território-limite da representação cinematográfica... ”. No que se refere à estrutura bipartite do filme, cf. a crítica de Jean-François Rauger. Ele afirma, em sua análise, que "Estrada perdida procede de um coup de force inaudito, de uma fratura anormal. O relato, como sob o efeito de um estranho fenômeno cerebral, quebra-se em seu meio. Como um erro de programa... ". RAUGER, J.-F. Crítica cinematográfica a Lost Highway publicada no jornal Le Monde em 16/01/1997. In: Cinémathèque Française. http://www.cinematheque.fr/fr/dans-salles/hommages-retrospectives/revues-presse/lynch/lost-highway.html. Acesso em 24/04/2015.

${ }^{16}$ Internet Movie Database: http://www.imdb.com/title/tt0116922/. Acesso em: 24/04/2015.

17 O recurso a "mundos possíveis" tem sido, desde Leibniz até a lógica modal contemporânea, um recurso usual para dar conta extensionalmente da semântica de certos termos (por exemplo, de termos modais tais como "necessidade", "contingência", etc.) e de certas proposições (por exemplo, de proposições contrafactuais). No caso de Lynch, porém, trata-se menos de percorrer mundos possíveis do que de criá-los - ou seja, de revelar os mundos que se entreveem sob ou sobre nosso mundo atual. Nesse sentido, os "mundos possíveis" não desempenham - não podem desempenhar - nenhuma função semântica, de fixação do sentido e, por isso mesmo, como veremos a seguir, não podem ser usados como base para uma interpretação qualquer.

${ }^{18}$ LYNCH, D.; GIFFORD, B. Lost Highway. London: Faber and Faber, 1997, p. 4.

${ }^{19}$ Cf. http://www.youtube.com/watch?v=UcTWtQAuAGU. Acesso em: 24/04/2015.

${ }^{20}$ Cf. http://www.youtube.com/watch?v=pD3_9yd72Ks. Acesso em: 24/04/2015.

${ }^{21}$ Como bem observa Marie-Noëlle Tranchant, em sua crítica de Estrada perdida: "Não conte com Lynch para propor-Ihes uma interpretação. Lynch é, por excelência, o autor que se ausenta de sua obra. Ele a entrega a vocês. Façam dela o uso que quiserem. No que the diz respeito, ele Ihes burilou luxuosamente o misterioso e o indecidível". TRANCHANT, M.-N.. Crítica cinematográfica a Lost Highway publicada no jornal Le Figaro em 15/01/1997. In: Cinémathèque Française. http://www.cinematheque.fr/fr/dans-salles/hommages-retrospectives/revues-presse/lynch/lost-highway.html. Acesso em 18/04/2015..

22 ŽlŽEK, S. Lacrimæ rerum. Ensaios sobre cinema moderno. Tradução de Isa Tavares e Ricardo 
Gozzi. São Paulo: Boitempo, 2009, pp. 138-139. Poucas páginas antes, a mesma dicotomia já fora apresentada: Žižek opõe aí as tentativas de "interpretação consistente" do filme (entre as quais inclui a sua própria) a um se deixar levar pela "multiplicidade inconsistente de cenas chocantes que nos bombardeiam" - nesse último caso, diriam os defensores dessa posição (ao menos, é o que eles diriam segundo Žižek), o que importa em Estrada perdida são apenas seus "efeitos visuais e sonoros"(p. 135).

${ }^{23}$ Ibidem, p. 139. Não é demais lembrar que, no contexto cultural no qual os livros de Deleuze sobre o cinema forma escritos, um de seus principais alvos era justamente a psicanálise estruturalista representada, por exemplo, por Christian Metz.

${ }^{24}$ Ibidem, p. 140.

${ }^{25}$ DELEUZE, G.; e GUATTARI, F. "28 de novembro de 1947 - Como criar para si um corpo sem órgãos". In: Mil platôs - Capitalismo e esquizofrenia, v. 3. Rio de Janeiro: Editora 34, 1996, p. 22.

${ }^{26}$ Ibidem, p. 23.

${ }^{27}$ Com esse termo, refiro-me aqui à peculiar noção de "leitura" desenvolvida por Deleuze em seus livros sobre o cinema.

${ }^{28}$ A alternativa "erótica" e (até certo ponto) formalista de Sontag para a interpretação "intelectualista" da hermenêutica não é, obviamente, compatível com a semiologia deleuziana, mas ela tem a seu favor, pelo menos, a bela concisão de seu título. Sontag, porém, compartilha com Žižek a ideia de uma oposição exclusiva e exaustiva entre interpretação de conteúdos e fruição de formas. Mais adiante em sua carreira intelectual, a própria Sontag passou a ver o livro de juventude de forma mais crítica. 